\title{
El bien jurídico protegido en el delito socioeconómico de administración desleal en España. El caso de la legislación poblana en perspectiva comparada*
}

Legal asset in the socio-economic crime of improper administration in Spain

\section{Xavier Nájera González**}

\section{RESUMEN}

El autor aborda la naturaleza jurídica de los bienes jurídicos en el ámbito socioeconómico, con especial referencia al ámbito societario, para determinar cuáles son los bienes jurídicamente protegidos en el delito de administración desleal español, con miras a determinar si tales aspectos pueden tener cabida en el delito de administración fraudulenta poblano, cuando éste se comete en el seno propiamente empresarial.

PALABRAS CLAVE: Delitos socioeconómicos, delitos societarios, bien juridico penal, bienes jurídicos generales y difusos, bienes jurídicos inmediatos y mediatos.

\begin{abstract}
The author presents a study on legal nature of legal assets in the socio-economic sphere, with special reference to corporate field, in order to determine legally protected assets in the crime of improper administration in Spain, and thus, to determine if these aspects can be present in the fraudulent administration crime, when this crime is committed at a business level.
\end{abstract}

KEY WORDS: Socio-economic crimes, corporate crimes, legal assets, general and diffuse legal goods, mediate and immediate legal assets.

\footnotetext{
* Recibido: 8 de septiembre de 2014. Aceptado: 1 de diciembre de 2014.

** Profesor de Derecho penal y Criminología en la Facultad de Derecho y Ciencias Sociales de la Benemérita Universidad Autónoma de Puebla, México (xnajerag@gmail.com).
} 


\section{Sumario}

1. Introducción

2. Determinación de la naturaleza del bien jurídico protegido en los delitos socioeconómicos, con especial referencia a los delitos societarios

3. Determinación del bien jurídico penalmente tutelado en el delito societario de administración fraudulenta tipificado en el artículo 295 del Código Penal español 4. Consideraciones sobre el bien jurídico patrimonio, tutelado en el delito de administración fraudulenta del artículo 404, fracción XVII, del Código Penal del Estado Libre y Soberano de Puebla

5. Conclusiones

\section{Introducción}

Los delitos societarios se caracterizan por la necesidad que ha tenido el Estado de criminalizar una serie de comportamientos que dada su deslealtad hacia la empresa, por quienes tienen a su cargo funciones de administración o gestión, o quienes participan con ellos en tales actividades, provocan un perjuicio económico a sus propios intereses, al de sus socios o acreedores. ${ }^{1}$

Por ello, el Código Penal español de 1995 suplió una laguna de antaño existente en ese rubro, en el que ya las voces doctrinales de ese país clamaban por su incorporación, y que se vieron primeramente reflejados en los diferentes proyectos que antecedieron a su existencia. ${ }^{2}$ Además de que en otros países europeos ya se constataba la existencia de delitos de esta clase, como sucedía, por ejemplo, en Francia, en el que ya se tipificaba "l'abus de biens et du credit" (artículos 437.3 y 425.4 de la Ley del 24 de julio de 1966), sancionando el uso de los bienes o del crédito en contra del interés social, en el seno de las sociedades anónimas y de responsabilidad limitada; "l'abus de puvoirs sociaux" (artículos 437.4 y 425.5 del propio texto), que castiga la utilización abusiva de los poderes sociales.

En Alemania, ya era patente la figura de la Untreue (artículo 266), que ha sido objeto de estudio separado por parte de la doctrina: el del tipo de "abuso de la fidelidad" (Missbrauchtatbestand) en el primer inciso, y el del tipo de la

\footnotetext{
1 De una manera más amplia, Sánchez Álvarez define a los delitos societarios como "un conjunto heterogéneo de conductas que comparten entre sí la circunstancia de haberse cometido con ocasión de la administración o dirección de una empresa social, y que consisten, en lo esencial, en una violación particularmente grave de los deberes confiados legal o contractualmente o en un abuso de los poderes que se detentan en función de la posición que se ocupa en aquélla, con perjuicio de los socios, de la sociedad o de terceros". Cfr. Sánchez Álvarez, Manuel M. Los delitos societarios, Aranzadi, Pamplona, 1996, pp. 44 y 45.

2 Sobre este tema, analizando el aporte en materia de delitos socioeconómicos en el proyecto de 1980, la propuesta de anteproyecto de 1983, el proyecto de 1992, el proyecto de 1994, hasta llegar al Código Penal de 1995 en España, vid. Martinez-Buján Pérez, Carlos. Derecho penal económico, parte general, Tirant lo Blanch, Valencia, 1998, pp. 44-56.
} 
"ruptura de la fidelidad" (Treubruchtatbestand) en el segundo. ${ }^{3}$ En Italia, por ejemplo, con la tipificación de la "violazione di obblighi inerenti alle funzioni di amministrazione attiva e di liquidazione nella generalità delle societa commerciali” (artículo 2623 c.c.), ${ }^{4}$ o en Portugal, con el delito de infidelidade tipificado en el artículo 319 del Código de 1982, y que ha mantenido el vigente de 1995 (Decreto Ley núm. 48/95, del 15 de marzo, en su artículo 224).

De ahí el por qué en el Código Penal de 1995 español se tipificara dentro del título xill, denominado "Delitos contra el patrimonio y contra el orden socioeconómico", el capítulo xill, "De los delitos societarios". Lo que denota ya, de lege lata, la necesidad de establecer una clara distinción entre los delitos patrimoniales clásicos y los propiamente socioeconómicos.

Y precisamente dentro de estos delitos socioeconómicos se enmarcan los delitos societarios, entre los que se encuentra tipificado, concretamente en el artículo 295 del Código Penal de 1995, el delito de "administración desleal o fraudulenta", y que se define expresamente de la siguiente manera:

Artículo 295. Los administradores de hecho o de derecho o los socios de cualquier sociedad constituida o en formación, que en beneficio propio o de un tercero, con abuso de las funciones propias de su cargo, dispongan fraudulentamente de los bienes de la sociedad o contraigan obligaciones a cargo de ésta causando directamente un perjuicio económicamente evaluable a sus socios, depositarios, cuentapartícipes o titulares de los bienes, valores o capital que administren, serán castigados con la pena de prisión de seis meses a cuatro años, o multa del tanto al triplo del beneficio obtenido. ${ }^{5}$

En cambio, en el Código Penal para el Estado Libre y Soberano de Puebla (México), dentro del capítulo decimoctavo, "Delitos contra las personas en su patrimonio", en su sección cuarta, "Fraude", se prevé el delito de "Administración fraudulenta", como una modalidad del delito de fraude específico, en el artículo 404, fracción XVII, con las sanciones que de acuerdo con el monto de lo defraudado establece el diverso 403 de esa propia legislación. ${ }^{6}$ Disposiciones legales que son del tenor literal siguiente:

3 Vid. Martinez-Buján Pérez, Carlos. El delito societario de administración desleal, Tirant lo Blanch, Valencia, 2001, p. 17.

${ }^{4}$ Sobre este delito cfr., inter alia, Foffani, Luigl et al. Diritto penale commerciale 2. I reati societari e la tutela penale del mercato mobiliare, coordinado por Nicola MAzzAcuva, Unione Tipografico-Editrice Torinese (UTET), Turín, pp. 297354.

${ }^{5}$ Visible en la página electrónica siguiente: https://www.boe.es/buscar/pdf/1995/BOE-A-1995-25444-consolidado. pdf [Consulta: 15.Enero.2015].

${ }^{6}$ Visible en la página electrónica: http://legislacion.scjn.gob.mx/LE/Reformas.aspx?idEdo=20\&tidLey=7625 [Consulta: 15.Enero.2015]. 
Artículo 403. El delito de fraude se sancionará:

1. Con multa de cinco a cincuenta días de salario y prisión de seis meses a tres años, si no se puede determinar el valor de lo defraudado o este valor no es superior a cien días de salario;

II. Con multa de cincuenta a doscientos cincuenta días de salario y prisión de tres a cinco años, si el valor de lo defraudado excediere de cien días de salario, pero no de quinientos;

111. Con multa de doscientos cincuenta a quinientos días de salario y prisión de cinco a siete años, cuando el valor de lo defraudado excediere de quinientos días de salario, pero no de mil, y

IV. Con multa de quinientos a mil días de salario y prisión de siete a diez años, cuando el valor de lo defraudado excediere de mil días de salario.

Artículo 404. Las mismas sanciones señaladas en el artículo anterior se impondrán:

[...]

xVII. Al que por cualquier razón tuviera a su cargo el manejo, la administración o el cuidado de bienes ajenos y perjudicare a su titular alterando en sus cuentas los precios o condiciones de los contratos, suponiendo operaciones o prestaciones o exagerando las que hubiere hecho, ocultando o reteniendo bienes, o empleare abusivamente los bienes o la firma que se le hubiere confiado.

De la lectura comparativa de ambos tipos penales se desprende que el delito de administración desleal español es un delito socioeconómico que se enmarca dentro de los denominados delitos societarios, dada su afectación en el ámbito empresarial. En cambio, en el delito de administración fraudulenta que se prevé en el Código Penal poblano sólo se advierte, en apariencia, una connotación protectora de índole meramente patrimonialista, de corte individualista, que pasa por alto una posible afectación de naturaleza socioeconómica, y ni qué decir del ámbito societario-empresarial. Todo ello obliga a formular la pregunta de ¿si tal diferencia en el seno del bien jurídicamente protegido entre ambos delitos resulta de trascendencia dogmática con miras al aseguramiento de una cabal protección jurídico-penal cuando, en el caso concreto, el delito en Puebla se cometa en el ámbito empresarial?

Para dar una respuesta satisfactoria a tal interrogante jurídica es menester hacer algunas reflexiones en torno a la doctrina europea del bien jurídico penal de los delitos socioeconómicos-societarios, para ver si tales reflexiones pueden tener cabida o no, en la correspondiente figura típica del derecho penal poblano. 


\section{Determinación de la naturaleza del bien jurídico protegido en los delitos socioeconómicos, con especial referencia a los delitos societarios}

Prima facie, debe señalarse que dentro de los bienes jurídico-penales, la doctrina europea ha distinguido entre los denominados bienes jurídicos generales y los bienes jurídicos difusos. Los primeros son intereses pertenecientes a la generalidad de las personas que se integran en la comunidad social. ${ }^{7}$ En tanto que los bienes jurídicos difusos ${ }^{8}$ no son intereses que afecten a la totalidad de las personas, sino concretamente a un sector de la población, es decir, a un grupo determinado de individuos. Por tanto, a diferencia de los intereses sociales generales que pertenecen a todos, los intereses sociales difusos son de naturaleza sectorial. ${ }^{9}$

De esa manera, los bienes jurídicos de los delitos socioeconómicos pueden ser generales, si se entiende al orden económico en sí, como la facultad interventora y reguladora de la economía estatal. Pero al mismo tiempo pueden ser un bien jurídico difuso si se entiende que con tal clase de delitos se protege el "orden económico de un determinado sector de dicha disciplina", por ejemplo el mercado bursátil, por cuanto este sector tiene su propio rol en el sistema productivo.

Así, la protección del orden económico en el ámbito penal juega un doble papel sumamente importante con base en el enfoque generalizado o particularizado que se otorgue al concreto objeto jurídico de tutela punitiva. ${ }^{10}$

\footnotetext{
${ }^{7}$ Algunos se refieren a ellos con el término de bienes jurídicos universales. Asi HASSEMER, quien dice que los bienes jurídicos universales son los "intereses de la mayoría", y que "son tan generales que no dejan ningún deseo sin satisfacer". Dice, por ejemplo, que se trata de la protección del "bienestar" de los hombres en un "sentido somático" en vez de la protección de la vida y la salud de las personas; de la salud pública; del funcionamiento del mercado; de la protección estatal empresarial o de la acumulación de datos comercial o administrativa. Cfr. HASSEMER, WinfRIED. "Derecho penal simbólico y protección de bienes jurídicos", en Nuevo Foro Penal, Bogotá, núm. 51, enero de 1991, p. 27. ${ }^{8}$ El término "interés difuso" fue acuñado por SGuBBI, quien originalmente lo concibió como una categoría alternativa o superadora del concepto material de bien jurídico, que nació para evitar la concepción limitada del derecho subjetivo. Cfr. SGubBi, F. "Tutela penale di «interessi diffusi»", en Loc, 1975, pp. 439 y ss. Aunque el referido término de "interés difuso", que ha sido asumido por la doctrina en general, deviene -en opinión de SoTo NAvARRO- de una desafortunada traducción del italiano, pues sostiene que debió haberse traducido como "interés difundido", pues aclara que dicho concepto hace referencia a "intereses que se presentan en modo informal y que se difunden a nivel de masas en ciertos sectores de la sociedad", lo que resulta congruente con su verdadero significado. Cfr. Soto NavarRo, SusAnA. La protección penal de los bienes colectivos en la sociedad moderna, Comares, Granada, 2003, pp. 193 y 194. ${ }^{9}$ Cfr. Torio López, A. Intereses difusos y derecho penal, Cuadernos de Derecho Judicial, 1994, xxxvi, p. 143.

10 Por eso, quienes admitan que el orden económico puede ser considerado como un bien jurídico penal directamente protegido en algunas figuras delictivas de ese carácter, hacen el matiz de considerar que ello sólo resulta sostenible en que se conciba que el orden económico como tal debe entenderse como una regulación jurídica que se concreta con un específico interés jurídico del Estado, que resulta ser diferente en cada delito en particular. Cfr.
} 
De esto se advierte que si se trasladan tales razonamientos al ámbito de los delitos societarios, -entre los que se encuentra el delito de administración desleal (en España)-, ahí se constata una afectación al "orden económico", entendido como bien jurídico general, pues con dicha conducta delictiva se aprecia una afectación sobre el sistema de regulación jurídica de la producción, distribución y consumo de bienes y servicios.

Pero al mismo tiempo, también en los delitos societarios se constata la necesidad de la existencia de un objeto de protección entendido como bien jurídico difuso, si lo que se busca proteger es la necesidad de brindar una tutela específica de la facultad que tiene el Estado de asegurar el "patrimonio societario"." De ahí que resulta de gran importancia garantizar, desde la óptica del derecho punitivo, la tutela del "patrimonio societario", a través de la tutela más generalizada de la buena marcha del "orden económico" en su conjunto. ${ }^{12}$

De esta forma, el "orden económico" y el "patrimonio societario" pueden concebirse como dos bienes jurídicos penales, que de manera efectiva, y en forma pluriofensiva, ${ }^{13}$ brindan protección jurídico-penal a las sociedades mercantiles desde una doble vertiente, que descansa tanto en el plano "ideológicoconceptual" como en el propiamente "material". ${ }^{14}$

Esto resulta ser así puesto que "el orden económico" en el delito de administración desleal ofrece una protección jurídica mediata, de índole "genérica", ${ }^{15}$

Bajo Fernández, Miguel et al. Manual de derecho penal. Parte especial. Delitos patrimoniales y económicos, 2a. ed., Madrid, 1993, p. 565.

$"$ Aunque haciendo referencia al "patrimonio social" como bien jurídico penalmente protegido en el delito de administración desleal, Bajo y Bacigalupo lo definen como "el conjunto de bienes y derechos económicos que revisten la apariencia jurídica de pertenecer a las entidades descritas en el artículo 297", y que son, al decir de este numeral, "toda cooperativa, caja de ahorros, mutua, entidad financiera o de crédito, fundación, sociedad mercantil o cualquier otra entidad de análoga naturaleza que para el cumplimiento de sus fines participe de modo permanente en el mercado". Vid. Bajo, Miguel y Bacigalupo, Silvina. Derecho penal económico, Centro de Estudios Ramón Areces, Madrid, 2001, pp. 598 y 599.

${ }^{12}$ De otra opinión FARALDo, quien considera que "[...] con los delitos societarios se trata de proteger indirectamente la integridad del orden económico, entendido éste siempre en un sentido amplio". Esto debido a que considera que los delitos societarios lesionan o ponen en peligro al patrimonio individual, ya que con ello lesionan frontalmente el buen funcionamiento de las sociedades mercantiles, impidiendo el desarrollo de las funciones que el ordenamiento les atribuye. Cfr. Faraldo Cabana, Patricia. Los delitos societarios, Tirant lo Blanch, Valencia, 1996, p. 71.

${ }^{13}$ Como dice Selcuk, "por regla general, cada norma delictiva no protege más que un interés, es decir, un objeto jurídico; mientras que en los delitos pluri-ofensivos se amparan numerosos bienes o intereses". Cfr. Selcuk, Samı. "El objeto del delito de estafa", en Cuadernos de Politica Criminal, Madrid, núm. 28, 1986, p. 195.

${ }^{14}$ Menciono "aparente", pues en rigor "lo característico de los delitos pluriofensivos es que ofrecen una protección específica a todos los bienes jurídicos cuyos menoscabos contemplan". Pues si no resulta ser asi, y en el caso concreto resultan afectados bienes distintos a los especificamente contemplados, esto deberá resolverse, en su caso, aplicando la técnica del concurso de infracciones, cuando proceda. Cfr. Doval Pals, Antonio. "Los delitos de fraude alimentario nocivo en el contexto de los delitos contra la seguridad colectiva", en Zúñiga Rodriguez, LauRa et al. (coords.). Derecho penal, sociedad y nuevas tecnologías, Colex, Madrid, 2001, p. 229.

${ }^{15}$ Y señalo "aparente" delito pluriofensivo porque, como señalan Сово y VIVES, "al efecto de delimitar si una determinada infracción es uni o pluriofensiva es preciso atender al bien o bienes juridicos inmediatamente tutelados 
dado que sólo resulta importante en el plano "ideológico-conceptual" de cara a su sistematización como delito socioeconómico. En tanto que desde el punto de vista material ofrece una protección específica, mediante la tutela del "patrimonio societario" que en forma efectiva resulta vulnerado de manera inmediata.

En efecto, si se realizan las debidas aclaraciones dogmáticas, la doctrina ha distinguido entre bienes jurídicos inmediatos y mediatos. ${ }^{16}$ En ese sentido, la diferencia radica en la manera en que directa o indirectamente se protejan los intereses o valores que el particular tipo penal demande. Así, los bienes jurídicopenales inmediatos son aquellos que resultan efectivamente lesionados en un ilícito pluriofensivo cualquiera, y son los que en sentido técnico resultan concretamente vulnerados en el caso particular.

De esta manera, el bien jurídico inmediato es aquel que técnicamente se protege en los tipos penales de forma directa o específica, y que se diferencia a su vez del bien jurídico mediato porque éste es el que se protege de forma indirecta por ese particular tipo penal. ${ }^{17}$

En esa tesitura, si se entiende al bien jurídico penal en su sentido más técnico, resulta que el bien jurídico penal inmediato, por consiguiente, debe concebirse como el elemento básico de protección de cualquier delito. En tanto que el bien jurídico penal mediato se refiere más bien a la razón que subyace en la protección normativa misma, a la llamada ratio legis. ${ }^{18}$

por la norma, siendo irrelevantes las consideraciones que puedan efectuarse de la contemplación del Ilamado «bien jurídico genéricon". Cfr. Cobo del Rosal, Manuel y Vives Antón, Tomás S. Derecho penal, parte general, 3a. ed., Valencia, 1991, p. 335.

${ }^{16}$ Así, quienes adhieren a esta posición reconocen que sólo el bien jurídico inmediato puede ser lesionado por el comportamiento del autor. De esa manera, el bien jurídico mediato no puede ser lesionado por su carácter institucional, ya que se trata de intereses abstractos que muy difícilmente pueden ser puestos en peligro por conductas individuales. Cfr. Echavaría Ramirez, Ricardo. "Consideraciones sobre el bien jurídico penalmente protegido por el delito de defraudación tributaria del art. 305 c.P. español", en Revista Electrónica de Ciencia Penal y Criminología RECPC 16-04 (2014), p. 13. Visible en la página electrónica: http://criminet.ugr.es/recpc/16/recpc16-04.pdf [Consulta: 24.Enero.2015].

17 Efectivamente, con acierto se dice que: "En el ámbito de los delitos económicos lato sensu es posible encontrar tipos orientados a la protección inmediata de bienes jurídicos de naturaleza individual (el patrimonio), aunque con proyección mediata sobre el orden económico, el cual debe identificarse con la ratio legis. Así, pues, la protección mediata del orden económico no tiene especial relevancia en la labor interpretativa, aunque sí incide en el ámbito de la lesividad abstracta, esto es, en el discurso sobre la intervención del derecho penal. En esta categoria suelen incluirse los delitos societarios". Cfr. Vega Gutiérrez, José Zamyr. El delito de uso de información privilegiada en el mercado de valores, especialmente en el derecho penal español (art. 285 CP), tesis doctoral, 16 de julio de 2010, p. 112. Visible en la página electrónica: http://dspace.uah.es/dspace/bitstream/handle/10017/9783/TESIS\%20doctORAL\%20 DEFINITIVA\%20IMPRESA.pdf?sequence $=1$ [Consulta: 24.Enero.2015].

18 Aunque habrá ocasiones en que las razones que motiven la incriminación de un comportamiento que hayan sido tomadas en consideración por el legislador, y la teleología político-criminal que subyace a ella, si bien se encuentran en la noción de bien jurídico, no deben ser confundidas con el mismo, pues la ratio legis puede verse satisfecha desde el momento mismo de la previsión legislativa, en tanto que el bien jurídico técnicamente tutelado siempre ha de resultar lesionado o puesto en peligro por la realización del delito. Cfr. Cobo del Rosal, Manuel y Vives Antón, Tomás S. Derecho penal, parte general, 4a. ed., Valencia, 1996, p. 295. 
Todo ello implica que el concepto de bien jurídico mediato tenga una función más teleológica, encaminada a determinar la finalidad objetiva de la norma en cuestión; por ende, dicho concepto debe vincularse con las particulares condiciones político-criminales que llevaron al legislador a la criminogénesis de determinada conducta, que dada su trascendencia ha resultado merecedora, necesaria y susceptible de protección punitiva.

Así las cosas, el bien jurídico penal inmediato está vinculado al tipo de injusto, y por ello debe ser abarcado por el dolo o la imprudencia del autor, y tiene relación con la función dogmática interpretativa en el descubrimiento del sentido y finalidad de cada tipo penal. En tanto que el bien jurídico penal mediato tiene un papel distinto, que se relaciona con otras funciones que tradicionalmente se han asignado al concepto de bien jurídico, como la de limitar y orientar el ius puniendi (derecho subjetivo del Estado a castigar); la de clasificar y sistematizar los diferentes grupos de delitos en un ordenamiento normativo, y la de tasar criterios para la medición y determinación de las penas.

En ese sentido, el intérprete de un particular tipo penal, al descubrir cuál es el bien jurídico penal mediato, no deberá acreditar que en un caso concreto se produjo la lesión o puesta en peligro de dicho bien, y menos aún constar si existió dolo o imprudencia referido al mismo; como, por el contrario, sí deberá realizar al determinar cuál es el bien jurídico penal inmediato de ese tipo en particular. ${ }^{19}$

Por lo que si se traslada la polémica antes referida a los delitos societarios, y concretamente al delito de administración fraudulenta, se encuentra la necesidad de hacer todavía más precisiones conceptuales.

Así, considero que el orden económico en este ilícito penal debe ser entendido como bien jurídico "general”, "mediato", "genérico" e "institucionalizado", habida cuenta que tiene una mera función representativa o simbólica, ${ }^{20}$ pues en los delitos societarios sólo tiene una función "espiritualizada", ya que sólo resulta ser útil para efectos teleológicos interpretativos y sistemáticos.

\footnotetext{
${ }^{19}$ En este sentido, cabe señalar que hay quien considera que los delitos societarios son delitos tanto de lesión como de peligro, ya que cuando afectan intereses individuales serán delitos de lesión, mientras que si atacan bienes supraindividuales serán de peligro. Cfr. Ríos Corbacho, José Manuel. El administrador de hecho en los delitos societarios, Servicio de Publicaciones de la Universidad de Cádiz, 2005, p. 28. De opinión contraria, González Cussac, quien estima que técnicamente es difícil que un delito sea a la vez de lesión y de peligro en esta clase de ilícitos, dada la diferente titularidad de los bienes jurídicos afectados. Cfr. González CussaC, José LuIs. "Delitos contra el patrimonio y el orden socio-económico" (xIII): "Los delitos societarios", en varios autores. Derecho penal, parte especial, 3a. ed., Valencia, 1999, pp. 544 y 545.

20 Hablando de derecho simbólico, HASSEMER señala que existe un acuerdo global respecto de la dirección en la cual se busca el fenómeno, entendido como la oposición entre "realidad" y "apariencia", entre "manifiesto" y "latente", entre lo "verdaderamente querido" y lo "otramente aplicado". Cfr. HASSEMER, WINFRIED, "Derecho penal simbólico y protección de bienes jurídicos", en Nuevo Foro Penal, núm. 51, enero de 1991, p. 22.
} 
En tanto que el bien jurídico difuso denominado "patrimonio social" debe entenderse en la administración fraudulenta como un bien jurídico inmediato, que al estar en aptitud de ser abarcado por el dolo del autor contenga una función dogmática en la hermenéutica interpretativa que el caso concreto demande.

Más aún porque este bien jurídico penal "patrimonio social" tiene una connotación colectiva que, a su vez, tiene un referente material individualizado en el denominado "patrimonio individual", conformado por cada uno de los socios integrantes de la empresa. Motivo por el que el "patrimonio social" constituye una manifestación "genuinamente tutelada", ${ }^{21}$ que se vincula a proteger el patrimonio individual de cada socio que la conforma. Situación que acaba con el carácter abstracto del bien jurídico colectivo "patrimonio social", para dotarlo de materialidad jurídica, al conformarse por la suma del "patrimonio individual" de cada integrante de la sociedad mercantil que corresponda. Lo que le dota de un contenido concreto e individualizable que complementa en el plano conceptual e ideológico al "orden socioeconómico", que, sin embargo, lo complementa en cuanto a su ubicación sistemática.

\section{Determinación del bien jurídico penalmente tutelado en el delito societario de administración fraudulenta tipificado en el artículo 295 del Código Penal español}

En atención a lo anteriormente expuesto, entiendo que en el delito de administración desleal o fraudulenta, tanto el bien jurídico penal denominado "patrimonio individual" como el bien jurídico colectivo o supraindividual "patrimonio social" resultan afectados.

El bien jurídico "orden económico" le imprime su carácter de delito socioeconómico, pero el bien jurídico penal "patrimonio social", en el que el primero se materializa, le da una connotación dogmática sistemática, sin la cual no tendría explicación alguna que el legislador del Código Penal español de 1995 hubiera ubicado la figura del delito de administración desleal bajo el epígrafe de los delitos societarios, y no propiamente bajo los propiamente patrimoniales.

Máxime que en el propio título xill el legislador hace mucho hincapié en intitularlo como "Delitos contra el patrimonio y contra el orden socioeconómico", pues de otra forma bastaría con la mera referencia a la protección "patrimonial"

${ }^{21}$ Es importante diferenciar entre bien jurídico institucionalizado (verbigracia, la seguridad del tráfico), que es el efectivamente lesionado, del bien jurídico genuino o complementado (por ejemplo, la vida, la integridad física) que es el puesto en peligro. Esto se debe a que en los delitos de peligro, con la utilización de bienes jurídicos colectivos, de lo que se trata es de que sirvan de barreras protectoras de la seguridad de bienes jurídicos individuales. Cfr. MÉnDEZ Rodriguez, CRistina. "Delitos de peligro y bienes jurídicos colectivos", Nuevo Foro Penal, núm. 44, junio de 1989, p. 177. 
para contemplar a los delitos socioeconómicos, pero con ello se obviaría el importante dato que constituye la protección del "orden económico" u "orden socioeconómico" como bien jurídico institucionalizado, que además de constituir una necesidad social de tutela punitiva en delitos de esta naturaleza, denota un plus de afectación distinto a la mera protección patrimonial individualista, dada su clara referencia en lo colectivo, como bien jurídico general.

De esa manera, el "orden socioeconómico" juega como bien jurídico que se protege en paralelo desde una perspectiva mediata, un papel teleológico y sistemático importante en la determinación y diferenciación de los delitos económicos o, si se prefiere, delitos socioeconómicos, y los propiamente patrimoniales. Pero, además, el bien jurídico "patrimonio social" juega un papel de mayor concretización en la hermenéutica y sistematización de tal delito dentro de los propiamente societarios, ${ }^{22}$ al vincularse con su referente material individual, que es la suma de "patrimonio individual" que cada socio aporta a la empresa.

En esa tesitura, al incardinarse los delitos societarios en el capítulo xill del mencionado título xill puede entenderse de dos formas: o bien que forman parte de los clásicos delitos patrimonialistas, o bien que constituyen un apartado de los delitos socioeconómicos.

Me inclino por estimar que los delitos societarios son genuinamente delitos socioeconómicos, dado que en su interés de proteger al patrimonio individual subyace además el interés mediato de proteger en paralelo al "orden socioeconómico". De ahí que a efectos sistemáticos y teleológicos, el bien jurídico penal "orden socioeconómico" tiene vital importancia en la interpretación dogmática, pues éste es el que imprime un rol importante en la hermenéutica de este delito, pues nos indica su correcta ubicación sistemática.

Pero además, en los delitos societarios, y concretamente en el de administración desleal español, juega un papel importante la protección del "patrimonio social" como bien jurídico genuino, que deriva de la protección complementada del bien jurídico individual denominado "patrimonio individual", que también resulta ser genuino, pues en este delito se constata una afectación pluriofensiva de tales objetos jurídicos.

Esto resulta ser así, pues para efectos dogmáticos las conductas típicas descritas de lege lata por el artículo 295 del Código Penal español hacen referencia a la "disposición fraudulenta" de bienes de la sociedad o a "contraer obligaciones a cargo de ésta". Lo que implica que los bienes de la sociedad constituyen el objeto de la acción, que guarda identidad con el objeto jurídico penal que denominó

\footnotetext{
22 Delitos societarios que tienen que ser interpretados con criterios penales que no pierdan sentido con los inevitables reenvíos a normas mercantiles, por naturaleza más mudables. Cfr. TerRadillos, Juan. Delitos societarios. El derecho penal en las sociedades mercantiles a la luz de nuestra adhesión a la CEE, AKAL-IURE, Madrid, 1987, p. 53.
} 
"patrimonio social", ${ }^{23}$ y que complementa al bien jurídico genuino "patrimonio individual”.

Sin embargo, debe precisarse que si bien la conducta típica de "disponer fraudulentamente" hace referencia directa a los bienes de la sociedad, en tanto que la diversa conducta alternativa de "contraer obligaciones a cargo de ésta" pareciera referirse a las obligaciones a cargo de la sociedad en sí, con independencia de sus bienes, debo matizar que ello no resulta factible del todo, habida cuenta de que quien contraiga obligaciones a cargo de una sociedad que administre de hecho o de derecho, las adquiere respecto de los bienes de la propia sociedad, y por ende afecta en forma inmediata a su "patrimonio social" como bien jurídico penal; dado que las sociedades cuentan con patrimonio y personalidad propia, independiente a las de sus "socios, depositarios, cuentapartícipes o titulares de los bienes, valores o capital". ${ }^{24}$

De esa manera, el objeto de la acción "bienes de la sociedad" tiene un referente "material" en el objeto jurídico "patrimonio social", que resulta ser el bien jurídico penal "genuino" de la afectación que de lege lata se exige del bien jurídico penal individual complementado "patrimonio individual", que sólo se ve lesionado, en forma secundaria o mediata, ${ }^{25}$ cuando primeramente se ha dado

${ }^{23}$ De otra opinión es Díaz Echegaray, quien considera que en el delito de administración desleal el bien jurídico protegido es el perjuicio económico al patrimonio social, a los depósitos constituidos por terceros en las oficinas de la sociedad, las cantidades recibidas por virtud de cuentas en participación, o incluso el daño originado a bienes, valores o capital cuya administración tengan encomendada. Lo que implica que el bien jurídico protegido sea mucho más amplio que el capital o patrimonio social, tratando de abarcar a cuantos bienes y derechos administren, aunque dejándose fuera de lege lata supuestos correspondientes al asegurado o a un tercero en virtud de un contrato de seguro. Cfr. Diaz Echegaray, José Luis. La responsabilidad penal de los socios y administradores, Montecorvo, Madrid, 1997, p. 177.

${ }^{24}$ De otra opinión es Nieto Martin, quien considera que el bien jurídico en el delito de administración desleal es el patrimonio de los socios, depositarios, cuentapartícipes o titulares de bienes, valores o capital que administre la sociedad, en tanto que el objeto de la acción es, según el propio tenor literal del precepto 295 del Código Penal, el patrimonio de la sociedad. Cfr. Nieto Martin, Adán. El delito de administración fraudulenta, Praxis, Barcelona, 1996, p. 254. En igual sentido opina Martínzz-Buján, entendiendo además al citado "patrimonio individual" de los sujetos antes descritos como el bien jurídico que se protege en "sentido técnico" en tal delito. Cfr. Martínez-Buján Pérez, Carlos. El delito societario de administración desleal, Tirant lo Blanch, Valencia, 2001, pp. 31-34. Así opina Mata MArtin, al considerar que el bien juridico en la administración desleal es el patrimonio individual, en tanto que el patrimonio social sólo juega el papel de objeto material. Cfr. Mata Martin, Ricardo. "Delitos societarios: administración desleal y demás figuras delictivas", en Empresa y derecho penal (1), Cuadernos de Derecho Judicial, Escuela Judicial, Consejo General del Poder Judicial, Madrid, 1998, p. 342. Matizando la cuestión al considerar al patrimonio de forma global como bien jurídico protegido en tal delito, mediante la pérdida o disminución de valor de una parte concreta del mismo, vid. Fernández Teruelo, Javier Gustavo, Los delitos societarios en el Código Penal español, Dykinson, Madrid, 1998 , pp. 328 y 329

25 Sin embargo, de otra opinión es MAYO CALDERón, quien prima facie considera que debe rechazarse la noción de "bien jurídico mediato", dado que esa expresión es confusa y perturbadora, al confundir en el concepto de bien jurídico en sentido técnico, con la diversa noción que constituye la ratio legis o finalidad objetiva de la norma, en que se pretende situar a dicho concepto. Cfr. MAYo CALDERón, BelÉn. La tutela de un bien jurídico colectivo por el delito societario de administración fraudulenta. Estudio del art. 295 del Código Penal español y propuesta de lege ferenda, Comares, Granada, 2005, pp. 14 y 15. 
una puesta en peligro tentada del bien jurídico colectivo "patrimonio social", que se encuentra adelantado en la barrera de protección punitiva.

Ello implica que para que se lesione al bien jurídico "patrimonio individual”, que de lege lata se materializa en el patrimonio de los "socios, depositarios, cuentapartícipes o titulares de los bienes, valores o capital" en la cantidad que le pertenezca a la sociedad, primeramente debe ponerse en peligro tentado al bien jurídico penal "patrimonio social" del que es titular la sociedad en sí.

Esto es así ya que la realización en grado de tentativa de alguno de los dos comportamientos típicos alternativos de "disponer fraudulentamente de los bienes de la sociedad" o de "contraer obligaciones a cargo de ésta" pone en peligro al "patrimonio social" de la sociedad. Peligro que finalmente se consuma en una lesión efectiva del "patrimonio individual" cuando, como lo exige el propio artículo 295 del Código Penal español, se cause directamente un perjuicio económicamente valorable para los "socios, depositarios, cuentapartícipes o titulares de los bienes, valores o capital" que administre de hecho o de derecho el autor de tales comportamientos típicos. ${ }^{26}$

Esto denota que en el delito de administración desleal o fraudulenta, el "patrimonio individual" es el bien jurídico penal que resulta inmediatamente lesionado, con posterioridad a la puesta en peligro, también inmediata, del "patrimonio social", al que complementa. ${ }^{27}$

Por ello, considero que el delito de administración fraudulenta es un delito pluriofensivo de lege lata, en el que tanto el "patrimonio social" como el "patrimonio individual" son los bienes jurídicos que deben ser abarcados por el dolo del autor. El primero, desde que da inicio la puesta en peligro mediante la realización de la conducta correspondiente en grado de tentativa, y el segundo, por lo menos en forma eventual, desde el momento de la lesión efectiva del resultado material, consistente en el patrimonio de los "socios, depositarios,

\footnotetext{
${ }_{26}$ Para Castro Moreno, la integridad del patrimonio social es, junto con la defensa de los patrimonios de los sujetos pasivos recogidos en el precepto, el bien jurídico protegido por el delito societario de administración desleal. Cfr. Castro Moreno, Abraham. El delito societario de administración desleal (art. 295 cP), Marcial Pons, Madrid, 1998, p. 186. En igual sentido opina DeL RoSAL, al considerar que la conducta descrita en el artículo 295 atenta contra el patrimonio social y contra el patrimonio de los socios, depositantes, cuentapartícipes o titulares de los bienes, valores o capital que administren los administradores de hecho o de derecho de la sociedad en cuestión. Cfr. Del Rosal Blasco, Bernardo. Los delitos societarios en el Código Penal de 1995, Tirant lo Blanch, Valencia, 1998, p. 140; ID. "Los nuevos delitos societarios en el Código Penal de 1995", en Martinez Bujan-Pérez, Carlos. I Congreso Hispano-Italiano de Derecho Penal Económico, Universidade da Coruña, 1998, pp. 133 y 134.

27 En cambio, Rodriguez Montañés considera que la mención a los socios se hace en cuanto tienen el carácter de titulares del patrimonio social, por lo que el tipo abarca también el perjuicio a éstos como objeto directo de protección. De ahi que estime que el objeto de protección sean los intereses patrimoniales de la sociedad (e indirectamente de los socios, en cuanto sean partícipes de la misma). Cfr. Rodriguez Montañés, Teresa. La responsabilidad penal del administrador desleal y los nuevos delitos societarios, McGraw-Hill, Madrid, 1997, pp. 123-125. En igual sentido, Faraldo Cabana, Patricia. Los delitos societarios, cit., p. 568.
} 
cuentapartícipes o titulares de los bienes, valores o capital" de la sociedad afectada. ${ }^{28}$

Y además de ello, dadas las características esenciales de este delito societario -y por ende, socioeconómico- este patrimonio individual, en el que se materializa la efectiva consumación del resultado material, es el claro referente material del bien jurídico penal "patrimonio social", que no constituye una mera creación abstracta o ideológica, pues éste sólo es apreciable en la medida que se considere, desde una perspectiva colectiva, como la suma del patrimonio individual de todos los que sean "socios, depositarios, cuentapartícipes o titulares de los bienes, valores o capital" que integren a la sociedad en cuestión, o bien, desde una perspectiva difusa, como los intereses penalmente protegidos de ese particular sector de la sociedad, consistente en el subsistema societario que en el caso concreto resultó afectado. ${ }^{29}$ Así, todo ello contribuye, desde la óptica del bien jurídico penal, a darle autonomía al delito de administración fraudulenta descrito por el artículo 295.

De igual manera, si se analiza el diverso ilícito de "apropiación indebida" previsto en el artículo 252 del ordenamiento punitivo español, ${ }^{30}$ desde la óptica

\footnotetext{
${ }^{28}$ En cambio, para Rodriguez-Mourullo el bien jurídico protegido en el delito de administración desleal sólo es el patrimonio de los socios, depositantes, cuentapartícipes o titulares de bienes, valores o capital administrados por la sociedad. Cfr. Rodriguez-Mourullo Otero, Gonzalo. "El bien jurídico protegido en los delitos societarios con especial referencia a la administración desleal", La administración desleal, Cuadernos de Derecho Judicial, Escuela Judicial, Consejo General del Poder Judicial, Madrid, 1999, p. 31. De la misma opinión es SÁnchez Álvarez, aunque agregando en forma mediata al patrimonio social. Cfr. Sánchez Álvarez, Manuel M. Los delitos societarios, Aranzadi, Pamplona, 1996, p. 180.

${ }^{29}$ En sentido similar FerRé Ouvé, quien señala que el Código Penal de 1995, al regular el delito de administración fraudulenta, no atiende exclusivamente a la naturaleza patrimonial del delito cometido, sino que el componente socioeconómico obliga a reinterpretar el bien juridico tutelado y las concretas características típicas que resultan enunciadas en el artículo 295 del Código Penal. Aunque reconoce, por otra parte, que resulta innegable que el delito en comento se estructura sobre la base de la lesión patrimonial, aunque en la administración fraudulenta se aprecia la inexistencia de una relación bilateral nítida entre autor y víctima, como ocurre en los delitos patrimoniales más tradicionales. Cfr. Ferré Olivé, Juan Carlos. "La administración social fraudulenta (art. 295 del Código Penal)", en Galán Corona, Eduardo y Garcia-Cruces, José A. (coords.). La responsabilidad de los administradores de las sociedades de capital. Aspectos civiles, penales y fiscales, Tecnos, Madrid, 1999, p. 129.

30 Tal disposición establece: "Artículo 252. Serán castigados con las penas del artículo 249 o 250, en su caso, los que en perjuicio de otro se apropiaren o distrajeren dinero, efectos, valores o cualquier otra cosa mueble o activo patrimonial que hayan recibido en depósito, comisión o administración, o por otro título que produzca obligación de entregarlos o devolverlos, o negaren haberlos recibido, cuando la cuantía de lo apropiado exceda de cuatrocientos euros. Dicha pena se impondrá en su mitad superior en el caso de depósito necesario o miserable".

A su vez, los diversos 249 y 250 del Código Penal de 1995 disponen:

"Artículo 249. Los reos de estafa serán castigados con la pena de prisión de seis meses a tres años, si la cuantía de lo defraudado excediere de 400 euros. Para la fijación de la pena se tendrá en cuenta el importe de lo defraudado, el quebranto económico causado al perjudicado, las relaciones entre éste y el defraudador, los medios empleados por éste y cuantas otras circunstancias sirvan para valorar la gravedad de la infracción".

"Artículo 250.1. El delito de estafa será castigado con las penas de prisión de un año a seis años y multa de seis a doce meses, cuando: $1^{\circ}$. Recaiga sobre cosas de primera necesidad, viviendas u otros bienes de reconocida utilidad
} 
del bien jurídico, y tomando en consideración la postura aquí defendida, la administración desleal o fraudulenta es un delito complejo o pluriofensivo que condiciona la necesaria puesta en peligro anticipada del "patrimonio social" (bienes de la sociedad) a la posterior lesión del bien jurídico "patrimonio individual" (de los titulares de tales bienes). En tanto que el delito de apropiación indebida es un delito simple que sólo afecta al patrimonio individual y que, dicho sea de paso, no constituye un delito especial impropio, como lo es la administración desleal, sino uno de realización común.

\section{Consideraciones sobre el bien jurídico patrimonio, tutelado en el delito de administración fraudulenta del artículo 404, fracción xvıl, del Código Penal del Estado Libre y Soberano de Puebla}

El delito de administración fraudulenta previsto como una modalidad del fraude específico en la legislación penal poblana, a primera vista, parece tener más parecido con el delito de "apropiación indebida" previsto en el artículo 252 del ordenamiento penal español, pues tiene una connotación aparentemente patrimonial. Ello parece desprenderse no sólo de su ubicación sistemática al incardinarse dentro de los delitos patrimoniales, sino de su propia redacción típica, que sugiere que a través de las conductas típicas alternativas de alterar, suponer, exagerar, ocultar, retener o emplear abusivamente bienes ajenos, cause un perjuicio a su titular, con motivo del manejo, administración o cuidado que el activo tiene respecto de los mismos.

Perjuicio que en la administración fraudulenta poblana parece necesariamente ser de índole patrimonial, pues de la redacción típica no se aprecia en una primera ojeada, ni siquiera de manera mediata, una afectación al bien jurídico "orden socioeconómico", como acontece con el diverso delito de administración desleal español, tipificado en el artículo 295 del Código Penal de 1995.

social. $2^{\circ}$. Se perpetre abusando de firma de otro, o sustrayendo, ocultando o inutilizando, en todo o en parte, algún proceso, expediente, protocolo o documento público u oficial de cualquier clase. $3^{\circ}$. Recaiga sobre bienes que integren el patrimonio artístico, histórico, cultural o científico. $4^{\circ}$. Revista especial gravedad, atendiendo a la entidad del perjuicio y a la situación económica en que deje a la víctima o a su familia. $5^{\circ}$. Cuando el valor de la defraudación supere los 50.000 euros. $6^{\circ}$. Se cometa abuso de las relaciones personales existentes entre víctima y defraudador, 0 aproveche éste su credibilidad empresarial o profesional. $7^{\circ}$. Se cometa estafa procesal.

Incurren en la misma los que, en un procedimiento judicial de cualquier clase, manipularen las pruebas en que pretendieran fundar sus alegaciones o emplearen otro fraude procesal análogo, provocando error en el juez o tribunal y llevándole a dictar una resolución que perjudique los intereses económicos de la otra parte o de un tercero. 2. Si concurrieran las circunstancias $4^{\mathrm{a}}, 5^{\mathrm{a}} 06^{\mathrm{a}}$ con la $1^{\text {a }}$ del número anterior, se impondrán las penas de prisión de cuatro a ocho años y multa de doce a veinticuatro meses". 
Esto es así, ya que en la administración desleal española, la afectación dañosa del "orden socioeconómico" claramente se aprecia de la lectura de su propia descripción típica, cuando ésta hace alusión concretamente a que el sujeto activo disponga fraudulentamente de los bienes de la sociedad o contraiga obligaciones a cargo de ésta que causen directamente un perjuicio económicamente evaluable a los socios, depositarios, cuentapartícipes o titulares de tales bienes.

Sin embargo, en el fondo, estimo que ambos tipos penales comparten una ratio legis que los anima, y que les imprime un común denominador preventivo, que consiste en el aseguramiento del buen comportamiento de los administradores a través de la punición de la deslealtad de los administradores de una cosa ajena, que se concreta en el patrimonio administrado. ${ }^{31}$ De ahí que el patrimonio societario o el patrimonio individual, que le es confiado a quien resultó ser un administrador desleal, se convierte en el objeto de protección punitiva por excelencia. Esto a pesar de que en sentido estricto parece no ser lo mismo el patrimonio individual que el patrimonio societario, pues este último reviste una connotación de índole socioeconómica que obliga a una protección sui generis, pues con el aseguramiento de la buena marcha de las empresas, a través del patrimonio del que ésta se compone, se obtiene el avance de la economía nacional e incluso de la economía global. ${ }^{32}$ Sin embargo, si se ven las cosas desde otro ángulo, el patrimonio individual integra finalmente el patrimonio social, a manera de referente material del segundo, lo que permite dar vida a este ulterior bien jurídico colectivo, que se conforma de la suma de tales bienes jurídicos individuales.

En efecto, con el Código Penal de 1995 España contribuyó al mundo jurídico con la creación del tipo penal de administración desleal, que tenía la intención de dar una respuesta eficaz a una serie de prácticas ilícitas en el seno societario que carecían de respuesta jurídico-penal, porque se daban gravísimas infidelidades del administrador, pero sin engaño previo al administrado y sin apropiarse tampoco de los bienes, de ahí que sus elementos no encuadraban ni en la estafa

\footnotetext{
${ }^{31}$ Por ello, con acierto BACIGALupo ha mencionado que el derecho penal no es ajeno al buen gobierno corporativo, al describir conductas típicas que tratan de cuestiones relacionadas en gran medida con la lealtad de los administradores y la protección de los titulares del patrimonio administrado. Cfr. BAcIgalupo, EnRloue. Falsedad documental, estafa y administración desleal, Marcial Pons, Madrid-Barcelona-Buenos Aires, 2007, p. 193.

32 Tan es asi que en el ámbito europeo, en mayo de 2003, la Comisión Europea publicó una comunicación (284/2003) sobre la modernización del derecho de sociedades y mejora del gobierno cooperativo, que hace referencia a temas que han sido objeto de importantes procesos penales en más de un Estado miembro. Asimismo, en mayo de 2006 la Comisión Nacional del Mercado de Valores hizo público su Código Unificado de Buen Gobierno de las Sociedades Cotizadas, en el que contiene un sistema de normas que orientan la administración y el gobierno de las empresas según criterios considerados como capaces de obtener el consenso del mundo empresarial respecto de una administración transparente y leal de las sociedades y la correspondiente protección de los accionistas. Cfr. BAcIgalupo, EnRIQUe. op. cit., pp. 194 y 195.
} 
(equivalente al fraude en Puebla) ni en la apropiación indebida (equivalente al abuso de confianza en Puebla). ${ }^{33}$ Situación por la cual resultó necesario legislar en ese ámbito, con un tipo penal que cubriera tales deficiencias jurídicas.

Así, una de las principales diferencias entre el delito de administración desleal en España y el delito de apropiación indebida radica en el hecho de que el administrador desleal del artículo 295 del Código Penal español actúa en todo momento como tal, puesto que lo hace dentro de los límites de sus funciones, de ahí que el exceso se mantiene dentro de sus propias funciones, aunque indebidamente ejercidas. Mientras que en la apropiación indebida, la deslealtad supone una actuación fuera de lo que el título de recepción permite, y no como sucede en la administración desleal, en donde la deslealtad se integra por el ejercicio de las facultades administrativas que indebidamente se han realizado, pero que no rebasan los límites de tal encargo del administrador, a pesar de lo indebidamente realizadas. ${ }^{34}$

Si se traslada tal razonamiento al ámbito penal poblano se advierte que en el fondo sí existe una semejanza importante entre la administración desleal española y la administración fraudulenta poblana, la cual subyace en que la primera (española) se comete por "los administradores de hecho o de derecho o los socios de cualquier sociedad constituida o en formación”, mientras que la segunda (poblana) se comete por quien "por cualquier razón tuviera a su cargo el manejo, la administración o el cuidado de bienes ajenos y perjudicare a su titular". Situación por la que resulta sumamente importante señalar que, en ambos casos, quien de facto o de iure funge como administrador de bienes ajenos comete el delito, precisamente, porque actuando en abuso de tales funciones, de manera desleal o fraudulenta, causa perjuicio a los titulares de los bienes que le fueron dados en administración (sea o no en el ámbito societario).

Situación que denota, a mi modo de ver, que en el delito de administración fraudulenta poblana no sólo debe apreciarse la existencia de un daño patrimonial propiamente dicho, sino que cuando éste sea cometido en el seno corporativo también podrá hablarse de un delito pluriofensivo, que necesariamente vulnerará, además del patrimonio individual, el patrimonio social de la particular empresa cuyo administrador, es decir, aquel que por cualquier razón tuviera a su cargo el manejo, la administración o el cuidado de bienes ajenos, perjudicare a su titular, en el propio ámbito de las funciones que le fueron encomendadas.

\footnotetext{
33 Cfr. Camacho Rosales, Francisco Javier. Apropiación indebida vs. administración desleal, Universidad Internacional de Andalucia, Curso de Experto Universitario en Derecho Penal: Aspectos Materiales y Procesales, 2013, p. 5. Visible en la página electrónica: http://dspace.unia.es/bitstream/handle/10334/2497/0441_Camacho.pdf?sequence=1.

34 Vid. sentencia del Tribunal Supremo 915/2005, del 11 de julio (España). Visible en la página electrónica: http:// www.poderjudicial.es/search/doAction?action $=$ contentpdf\&tdatabasematch $=$ TS\&reference $=1236386 \&$ links $=\% 2291$ 5/2005\%22\&toptimize=20050811 \&tpublicinterface=true [Consulta: 25.Enero.2015].
} 
De ahí que en ese supuesto concreto, a través de la afectación del patrimonio social también podrá ser patente un daño al orden socioeconómico mexicano, pues la economía nacional, indefectiblemente, se ve ultrajada por quien en el seno societario incumple su deber de lealtad en las facultades administrativas que le fueron conferidas.

Situaciones que, por ende, deben ser abarcadas por el dolo del autor para entender colmado el tipo poblano en cuestión en esos casos concretos en que se afecte el seno corporativo, lo que sólo abarcará tanto al patrimonio individual como al patrimonio social. No obstante que este último, de manera indirecta (mediata), también afecte al orden socioeconómico en su conjunto. Todo ello bajo la idea de que el patrimonio social condiciona la afectación mediata del orden socioeconómico mexicano, pues éste necesariamente se ve afectado cuando no funcionan adecuadamente las empresas. De ahí que sólo cuando la administración fraudulenta adquiera un tinte empresarial también podrá ser considerada como un delito socioeconómico; aunque, de suyo, siempre tenga la calidad de delito patrimonial propiamente dicho, lo que sucederá en este último caso, por supuesto, sólo cuando la afectación al patrimonio no trascienda de lo meramente individual.

\section{Conclusiones}

Primera. Los delitos societarios se caracterizan por la necesidad que ha tenido el Estado de criminalizar una serie de comportamientos que dada su deslealtad hacia la empresa, por quienes tienen a su cargo funciones de administración o gestión, o quienes participan con ellos en tales actividades, provocan un perjuicio económico a sus propios intereses, al de sus socios o acreedores.

Segunda. En el Código Penal español de 1995 se tipifica el delito de administración desleal dentro del título xill, denominado "Delitos contra el patrimonio y contra el orden socioeconómico", en el capítulo xill, "De los delitos societarios". Lo que denota ya, de lege lata, la necesidad de establecer una clara distinción entre los delitos patrimoniales clásicos y los propiamente socioeconómicos.

Tercera. El bien jurídico penal "orden económico" en el delito de administración desleal español ofrece una protección jurídica mediata, de índole "genérica”, dado que sólo resulta importante en el plano "ideológico-conceptual", de cara a su sistematización como delito socioeconómico. En tanto que desde el punto de vista material ofrece una protección específica mediante la tutela del "patrimonio social" que en forma efectiva resulta vulnerado de manera inmediata. 
Cuarta. Por tal motivo, considero que el orden económico en este ilícito penal debe ser entendido como bien jurídico "general", "mediato", "genérico", e "institucionalizado", habida cuenta que tiene una mera función representativa o simbólica, pues en los delitos societarios sólo tiene una función "espiritualizada”, ya que sólo resulta ser útil para efectos teleológicos interpretativos y sistemáticos. En tanto que el bien jurídico difuso denominado "patrimonio social" debe entenderse en la administración fraudulenta española como un bien jurídico inmediato.

Quinta. Concretando aún más el objeto de protección jurídica de la figura hispana, considero que el delito de administración fraudulenta español es un delito pluriofensivo de lege lata, en el que tanto el patrimonio social como el patrimonio individual son los bienes jurídicos que deben ser abarcados por el dolo del autor. El primero, desde que da inicio la puesta en peligro mediante la realización de la conducta correspondiente en grado de tentativa, y el segundo, por lo menos en forma eventual, desde el momento de la lesión efectiva del resultado material, consistente en el patrimonio de los "socios, depositarios, cuentapartícipes o titulares de los bienes, valores o capital" de la sociedad afectada.

Sexta. Ahora bien, si tales reflexiones se trasladan al ámbito penal poblano, concretamente al ámbito del delito de administración fraudulenta, estimo que esta figura típica comparte una misma ratio legis con el diverso delito de administración desleal hispano, debido a que en ambos lo que se busca resguardar es el buen comportamiento de los administradores de las cosas ajenas, a través de la prohibición de la deslealtad de sus funciones encomendadas, en el ámbito del patrimonio administrado.

Séptima. Por ello, estimo que el patrimonio social, o el patrimonio individual, que le es confiado a quien resultó ser un administrador desleal en ambos tipos penales (español y poblano) se convierte en el objeto de protección punitivo por excelencia. Esto, a pesar de que en sentido estricto parece no ser lo mismo el patrimonio individual que el patrimonio societario (social), pues este último reviste una connotación de índole socioeconómica, que obliga a una protección sui generis, ya que con el aseguramiento de la buena marcha de las empresas, a través del patrimonio del que ésta se compone, se obtiene el avance de la economía nacional, e incluso de la economía global.

Octava. Sin embargo, si se ven las cosas desde otro ángulo más concreto, el patrimonio individual también se integra finalmente con el patrimonio social, dado que el primero es el referente material del segundo, pues el patrimonio individual es el que da vida al patrimonio societario (social), que se compone de las suma de los primeros. 
Novena. De esa manera, estimo que en el delito de administración fraudulenta poblano, además de la lesión patrimonial propiamente dicha que lo caracteriza -inclusive desde la rúbrica bajo la cual se incardina en el Código Penal correspondiente-, también es patente una afectación al patrimonio societario (social) cuando este delito de administración fraudulenta poblano sea cometido en el ámbito corporativo. Esto resulta ser así, pues cuando se afecta el seno de las empresas este delito adquiere el carácter de delito pluriofensivo, ya que la particular afectación del patrimonio individual trasciende al patrimonio societario (social) de la específica empresa afectada. De esta forma, la específica conducta cometida por aquel sujeto activo que -como señala el tipo- "por cualquier razón tuviera a su cargo el manejo, la administración o el cuidado de bienes ajenos", y a través de ello "perjudicare a su titular", implica que no sólo vulnere el patrimonio individual, sino también el societario (social), ya que lo hace, precisamente, en el propio ámbito de las funciones que le fueron encomendadas, tal como acontece en el tipo penal español.

Décima. Motivos todos ellos por los que estimo que en el ámbito corporativo poblano, cuando se comete el delito de administración fraudulenta debe constatarse junto a la afectación del patrimonio individual, también la del patrimonio societario (social), en virtud de que este último es el que le imprime, de manera mediata, una afectación al "orden socioeconómico" mexicano en su conjunto; dado que la economía nacional, indefectiblemente, se ve ultrajada por quien en el seno societario incumple su deber de lealtad en las facultades administrativas que le fueron encomendadas.

Décima primera. Sin embargo, el dolo del autor sólo debe comprender la vulneración del patrimonio individual y del patrimonio social cuando en el seno corporativista poblano se cometa administración fraudulenta, pues téngase en consideración que éstos son los bienes jurídicos que resultan inmediatamente (directamente) afectados; no obstante que el último de ellos condicione a su vez la afectación mediata (indirecta) del orden socioeconómico mexicano. De ahí que en esos casos, el diseño típico de la administración fraudulenta poblana también deba considerarse un delito socioeconómico cuando de facto afecte el seno empresarial en sus funciones garantes de la economía nacional. 